\title{
Allo-Network Drugs: Extension of the Allosteric Drug Concept to Protein- Protein Interaction and Signaling Networks
}

\author{
András Szilágyi ${ }^{1,2, *}$, Ruth Nussinov ${ }^{3,4}$ and Péter Csermely ${ }^{1}$
}

\author{
${ }^{1}$ Department of Medical Chemistry, Semmelweis University, P.O. Box 260. H-1444 Budapest 8, Hungary; ${ }^{2}$ Institute of \\ Enzymology, Research Centre for Natural Sciences, Karolina ut 29, H-1113 Budapest, Hungary; ${ }^{3}$ Center for Cancer Research \\ Nanobiology Program, SAIC-Frederick, Inc., National Cancer Institute, Frederick National Laboratory for Cancer Re- \\ search, Frederick, MD 21702, USA and ${ }^{4}$ Sackler Institute of Molecular Medicine, Department of Human Genetics and \\ Molecular Medicine, Sackler School of Medicine, Tel Aviv University, Tel Aviv 69978, Israel
}

\begin{abstract}
Allosteric drugs are usually more specific and have fewer side effects than orthosteric drugs targeting the same protein. Here, we overview the current knowledge on allosteric signal transmission from the network point of view, and show that most intra-protein conformational changes may be dynamically transmitted across protein-protein interaction and signaling networks of the cell. Allo-network drugs influence the pharmacological target protein indirectly using specific inter-protein network pathways. We show that allo-network drugs may have a higher efficiency to change the networks of human cells than those of other organisms, and can be designed to have specific effects on cells in a diseased state. Finally, we summarize possible methods to identify allo-network drug targets and sites, which may develop to a promising new area of systems-based drug design.
\end{abstract}

Keywords: Allo-network drugs; allosteric drugs; interactome; protein-protein interaction networks; protein structure networks; signaling networks.

\section{INTRODUCTION}

Fast and affordable drug development is a requirement that contrasts with the current state of drug discovery. Drug development often fails because the development process does not always take into account the vast complexity of the cell and the robustness of its networks. In recent years, systems level and network analyses have become increasingly applied methods in drug design [1-14].

In this review, we first give a network-focused overview of how allosteric changes propagate within proteins, and how this signal transduction process can be extended to protein complexes and larger segments of protein-protein interaction and signaling networks. Further, we describe the benefits and the limitations of network-based methods to analyze allosteric action. Then we introduce the concept of allo-network drugs [15], i.e. drugs acting indirectly, via the inter-protein propagation of changes in cellular networks. We show that allo-network drugs may have special benefits in human cells, and may be designed to have specific effects on cells of diseased organisms. The review is concluded by the suggestion of several methods to identify allo-network drug targets and their binding sites including determination of network centralities, network hierarchy, controllability, assessment of perturbation propagation in networks, the analysis of correlated motions, reverse engineering methods to reveal central and less frequently used pathways, analysis of evolutionary conservation, as well as of biological

*Address correspondence to this author at the Institute of Enzymology, Research Centre for Natural Sciences, Hungarian Academy of Sciences, Karolina ut 29, H-1113 Budapest, Hungary; Tel.: +36 1 2793148; Fax: +36 1 4665465; E-mail: szia@enzim.hu disease-related systems data or system-level responses of the cell to drugs. We conclude that the development of allonetwork drugs appears as a promising new trend in drug design.

\section{THE PROPAGATION OF ALLOSTERIC EFFECTS AND PROTEIN STRUCTURE NETWORKS}

\subsection{The Concept of Allostery}

Several questions of protein dynamics such as the mechanism of allosteric changes gained much attention in the last century [16-22] but have not been completely elucidated yet. The molecular mechanisms of allostery have been typically discussed in terms of two classical models, the Monod-Wyman-Changeux (MWC) [23] and the KoshlandNémethy-Filmer (KNF) [24] models. Although these models were originally developed for describing allostery in homooligomers, their modernized versions also apply to monomeric proteins and other types of allosteric systems [25]. Both models assume that the protein can exist in two major conformations (e.g. tense and relaxed or active and inactive). According to the MWC model, equilibrium exists between the two conformations at all times, and the binding of the allosteric effector only modifies this equilibrium, causing a population shift [26]. In contrast, the KNF model assumes that the new conformation does not pre-exist before the binding of the effector but is instead induced by the binding event through a series of sequential steps. Experimental evidence supports the MWC model in many cases, such that it has been argued that it can claim victory [27], even though it has been acknowledged that local ligand-dependent movements may occur in agreement with the KNF mechanism. 
Others have argued that the MWC and KNF scenarios are just extremes of a range of possible allosteric mechanisms [28].

A modern extension of the MWC mechanism stresses that most proteins do not exist in only two possible states but form a large ensemble of states, and the allosteric change represents a redistribution of population intensities within this ensemble, i.e. a population shift [29]. In addition, allostery may occur without a conformational change [30,31], which led to the new concept of dynamically driven allostery [32] and the notion that all proteins may be capable of being allosterically regulated. A recent classification of allosteric mechanisms considers the extent of conformational change, and whether the allostery is driven by enthalpy, entropy, or both [33].

\subsection{Communication Pathways and Intra-Protein Net- works}

Regardless of the particular mechanism of allostery, it is recognized that information is in some way transmitted from the allosteric site to the substrate site, which implies the existence of communication pathways within the protein. Therefore, considerable experimental and computational effort has been devoted to discovering these pathways. It should be noted, though, that allostery has also been conceptually understood in purely thermodynamic terms, as in the ensemble view of allostery [34], which does not require the existence of specific pathways for the propagation of allosteric information.

The notion of intra-protein communication pathways inspires a network view of proteins. In this view, the protein is represented as a graph where nodes are (usually) amino acid residues and edges are defined based on some relationship between residues [35-45]. Communication from one site to another may thus occur along the edges of the graph.

As detailed in the following examples, there are many ways of defining networks within proteins. The procedure may start with a single structure, several structures (e.g. inactive and active forms), or an ensemble of structures obtained from molecular dynamics (MD) simulations or other approaches. Edges (weighted or unweighted) may be defined based on a simple distance cutoff criterion, interaction strength or energy, the comparison of structures, or an analysis of the ensemble. Experimental results are also used to define various networks within proteins.

\subsection{Properties of Protein Structure Networks}

The properties of protein structure networks (networks based on static structures) have been studied in detail [3545]. When the network is defined based on a distance cutoff, interaction cutoff or energy cutoff, it undergoes a percolation transition in a narrow range of the cutoff as the size of the largest connected component increases to eventually cover the whole protein $[40,46]$. The clustering coefficient tends to be homogeneous in the protein core, and characteristic path lengths of residues have been shown to correlate well with residue fluctuations [39]. Hubs tend to connect secondary structure elements, and have a preference for certain amino acids (mainly aromatic ones and arginine) [40].
It has been shown that residues with a high closeness index in the network tend to be functionally important, and are often at active sites [47,48]. Networks spanning proteinprotein interfaces have also been analyzed, with the general finding that hot spots at such interfaces tend to occur in clusters and are highly central [49-52]. In addition, protein structure networks have been used in studies of protein folding and unfolding [53-56].

\subsection{Methods to Identify Allosteric Pathways in Intra- Protein Networks}

Once an intra-protein network has been defined, various techniques can be used to find allosteric communication pathways within the network. One common method is to search for shortest paths connecting the allosteric and substrate sites [57-65]. This method identifies the residues most frequently occurring along these shortest paths. Another concept that is often embraced is to consider the protein as a set of modules (subgraphs with many connections within them but few connections between them). It has been shown that many proteins have a modular architecture, with modules corresponding to (often functionally distinct) subdomains. Residues between modules tend to be conserved and more rigid, and are thought to be involved in allosteric communication [66-69]. Several studies have employed the concept of modules or a related notion [69-71].

\subsection{Statistical Coupling Analysis}

In 1999, Lockless and Ranganathan [72] published an influential paper that introduced the idea of allosteric communication pathways, which inspired many experimental and computational studies. In this paper, the authors used statistical coupling analysis (SCA), a technique that uses a multiple sequence alignment to identify a coevolving set of residues in a protein family, to identify in the PDZ protein family a sparse network of residues representing what they called evolutionarily conserved pathways of energetic connectivity. Point mutations have been used to experimentally confirm the energetic coupling between the residues in the network. This method was then applied to reveal the communication pathways in a number of other proteins [73-77], and the predictions of the original paper have been supported by NMR measurements [78]. Although these studies showed the success of the SCA method, comparison with thermodynamic coupling data from double mutant cycles showed that while SCA does find some of the physically close, coupled residues, it does not find all of them [79]. Indeed, an exhaustive study using double mutant cycles found that coupling is not a special property of the residues in the coevolving network originally identified for the PDZ family [80]. A more recent lattice model study also noted some apparent discrepancies between SCA and mutational studies [81]. In spite of these apparent limitations, SCA continues to be successfully used in various studies [82-85].

\subsection{Networks from Experiments}

Although there are many computational techniques to detect allosteric communication pathways, it is difficult to discover those directly using experimental methods. As mentioned, SCA results were validated by mutational studies. 
Energetic coupling between residues can be reliably measured by double mutant cycles. However, a full energetic description of an allosteric pathway requires the examination of higher-order couplings, which can only be performed by triple, quadruple, etc. mutants. Clearly, the number of required constructs quickly grows prohibitively high. In an impressive study, 46 different mutants were used to reveal a highly cooperative, sharply delineated allosteric pathway in a voltage-gated potassium channel [86]. Energetic couplings were found to be highly anisotropic, not corresponding to a distance relationship, which suggests that there is an actual pathway of successive physical deformations.

NMR based techniques have been used to discover allosteric communication pathways in a number of proteins, with remarkable results $[87,88]$. Of special interest is the discovery of dynamic couplings and allosteric behavior in a nonallosteric protein, eglin c [89]. It was demonstrated that energy transmission is unidirectional, i.e. perturbing the protein at one site may elicit a change at another site, but this process does not always occur in the reverse direction. The networks of dynamical couplings were revealed in several different mutants of eglin c, and were found to be different. In one mutant that showed subtle conformational changes from the wild-type protein, the network of dynamical couplings was not physically contiguous. The propagation of allosteric signals was explained by a change in residue rotamer populations [89].

Recently, a highly powerful technique named "chemical shift covariance analysis" (CHESCA) was developed and validated by mutational studies $[90,91]$. The method provides a detailed picture of both the structurally and the dynamically mediated allosteric changes, quantitatively describing the relative contribution of each residue to binding and allostery.

\subsection{Multiple Pre-Existing Pathways}

The growing number of experimental and computational studies of allosteric communication pathways led to the concept that there are multiple pathways, which pre-exist before the binding of the allosteric effector, much like all functional conformations pre-exist in the conformational ensemble before an effector is bound [92]. Major and minor pathways may exist as suggested by the different effect of mutations upon the allosteric signal transmission. An MD based computational analysis of communication pathways in MettRNA synthase, however, indicated that only fragments of pathways are present in the apo states of the protein, with the full pathway only appearing when both substrates are bound [59]. This indicates the dependence of various pathways on subtle structural changes. A given pathway may only preexist in a scarcely populated subset of the native ensemble and thus may not be readily detected in MD simulations.

\subsection{Allosteric Communication Pathways from Static Structures}

A number of studies simply used a single structure or a small number of structures to define networks, and extract communication pathways. In myosin, this method was used to identify shortest paths between the ATP binding site and the lever arm, defining a communication pathway by con- served residues along the paths [60]. Another study identified those conserved residues that had the largest contribution to maintaining short paths within the protein structure network; the results showed good agreement with experimental findings for 7 protein families [57]. For proteins undergoing a clear conformational change due to allostery, pairs of structures can be used to obtain an insight into the allosteric mechanism [93]. It was found that a communication pathway is best identified by combining the network of rigid substructures with the network of contact rearrangements [94].

For a better description of information flow in the network, some studies use an information theoretical approach, converting the protein structure network into a Markovian model of information propagation [71,95-97]. By defining soft clusters in the Markovian network and identifying hub and 'messenger' residues, two main communication pathways were discovered in the GroEL-GroES system [71]. In a later study, it was shown that the commute time between two residues (as calculated from the Markov propagation model) is proportional to the fluctuations in the distance between these residues (as calculated from an elastic network model), thereby bridging the gap between information theory and physics based models [98].

\subsection{Communication Pathways from Elastic Network Models}

Elastic network models (ENMs) are various coarsegrained models of proteins that are typically defined from a single protein structure based on a residue-residue distance criterion, and studied by normal mode analysis [99]. Such models have proven successful for describing functional motions (including allosteric motions) in proteins, especially when the protein consists of large, rigid regions connected by more flexible linker regions [28,100]. ENMs have been used in various ways to define communication pathways. In the "structural perturbation method", the response of the network to a local structural perturbation is mapped out to define an allostery wiring diagram [101,102]. The similar "perturbation response scanning" method examines the displacement of residues when a force is applied on a selected residue [103]. A recent "electro-elastic network model" attempts to account for hydration, and is used to study the effect of solvation upon allosteric changes [104].

\subsection{Allosteric Communication from an Ensemble of Structures}

Recognizing the fact that proteins are dynamic entities, many techniques have been developed to define communication pathways in proteins from ensembles of structures. Molecular dynamics simulation (MD) is the most common method to generate ensembles of protein conformations. Once an MD trajectory is generated, the edges of a residue network are defined based on various quantities obtained by analyzing the trajectory. Edges between residues may be defined based on the correlation of displacements of the atoms (usually the $\mathrm{C} \alpha$ atom) $[59,61,64,105]$, the fluctuation of $\mathrm{C} \alpha-\mathrm{C} \alpha$ distances [106,107], generalized correlations [63], interaction energy correlations [108,109], mutual information between torsion angles [110], and discretized backbone 
conformations of segments [65]. In several cases, this network was further filtered or combined with distance based networks to ensure physical contact between correlated residues. The resulting network was then analyzed by the same methods as those used for static structures, i.e. finding shortest paths, hubs, clusters, modules, etc.

A different ensemble-based approach has been adopted by Hilser and colleagues [111,112]. Instead of generating an ensemble of actual conformations, a statistical mechanics approach is used. The COREX algorithm generates states with all possible combinations of locally unfolded or folded segments, and the energies of these states are estimated. In this approach, the energetic couplings between residues can be determined. Using energetic perturbations, the method reveals the cooperative network of the protein, and it can also determine the global allosteric response to mutations [113]. A remarkable conclusion arising from this approach is that cooperative coupling between sites does not require the existence of a specific energetic pathway. Instead, such coupling can be explained by the hierarchy of energetically excited states in the native ensemble. The validity of the approach was experimentally confirmed by creating a new allosteric effect by increasing the probability of some locally unfolded states in adenylate kinase, without changing the native structure [114].

\subsection{Energy Propagation in Proteins}

An allosteric effect can be regarded as a local energetic perturbation of a protein, which then propagates within the protein matrix to eventually reach the substrate site [115]. Several studies have been devoted to the investigation of energy transmission processes within proteins. The investigation of vibrational energy flow on all-atom models [116] found that the flow is anisotropic and the protein can be approximated as a percolation cluster [117] with a fractal dimension $\sim 2.5$. Energy is transferred between vibrational modes via anharmonic coupling. Based on a similar normal mode analysis, frequency-resolved communication maps were constructed for myoglobin [118]. At low frequencies, modes are global, and some channels are observed that could transfer energy away from the heme group. The communication map resembles the contact map. At higher frequencies, however, the map is very frequency-dependent. It should be noted that energy transfer by these processes is typically much faster (on the picosecond time scale) than most allosteric processes, therefore the relevance of these energy flow channels to allostery is uncertain.

Energy flow was also studied by elastic network models. Using an anharmonic model, it was shown that "discrete breathers", localized vibrational modes easily form in proteins at the stiffest regions, and are able to pump and store energy from neighboring sites. Thus, energy can 'jump' from site to site via this mechanism, often covering long distances $[119,120]$. In a Gaussian network model, the correlations between the energy fluctuations of residues were calculated, and were found to define an interaction pathway which was similar to the pathway defined by the co-evolving network of residues in the PDZ domain [121].

Energy flow within proteins was also investigated by a number of $\mathrm{MD}$ techniques. In the method of anisotropic thermal diffusion, a single amino acid is suddenly heated to $300 \mathrm{~K}$ while the rest of the protein is at $10 \mathrm{~K}$, and the diffusion of heat within the protein is monitored [122-124]. In pump-probe MD, selected atoms are excited by oscillating forces, and the transmission of the oscillations to other parts of the protein is monitored [125]. Similar methods are based on measuring the times energy is transmitted from the site of perturbation to other residues [126,127], and the time correlations of the energy flow between residues [128]. Although the perturbations used in these methods may be unphysically large, all these methods reveal the anisotropy and pathways of intra-protein energy transmission. Often, the communication pathways found by these methods are similar to those identified by other methods such as SCA.

A method has been developed to quantitate the local energetic frustration in proteins [129]. 'Frustratograms', networks of minimally and highly frustrated residue pair interactions, were calculated for a number of proteins, and it was shown that the regions that reconfigure during an allosteric conformational change tend to be enriched in patches of highly frustrated interactions [130]. This and similar findings have led to the idea that intra-protein communication may occur via a front of highly frustrated residues, and ligand binding may induce a flipping of residues within a 'frustration tube' [28].

Our current understanding indicates that allosteric changes may have two major molecular mechanisms. In allosteric proteins where signaling involves only a small number of amino acids, a switch-type conformational change is typical. When allosteric signaling involves a large number of amino acids signals usually propagate at multiple, seemingly fuzzy trajectories which tend to converge at inter-domain boundaries. While protein segments involved in switch-type allosteric changes may be more rigid, protein segments harboring multiple trajectories may be more flexible. Some proteins may have a mixture of the above two mechanisms for the propagation of conformational changes. If the binding of an allosteric effector makes certain protein segments more rigid, the signal may propagate by a mechanism closer to the first, switch-type mechanism, resulting in an efficient, saltatoric signal transduction. This can be conceptualized as the propagation of a 'rigidity-front' $[1,45,131]$. The 'rigidization' of a protein segment may accelerate the propagation of the allosteric change within the segment and induce similar changes in the neighboring segment. Rigidity front propagation may use sequential energy transfers [22,120], and thus may significantly increase the speed of the allosteric change $[1,45]$. The rigidity front propagation model combines elements of 'rigidity propagation' [132-134] with the 'frustration front' concept of Zhuravlev and Papoian [28], and it is in agreement with the recent proposal of Dixit and Verkhivker [135] suggesting an interaction network of minimally frustrated (rigid) anchor sites and locally frustrated (flexible) proximal recognition sites to play a key role in allosteric signaling.

\subsection{Finding Allosteric Sites by Network-Based Methods}

Discovering new allosteric sites in proteins opens up a new way of designing more specific drugs [87]. Thus, it is of interest to develop methods that can identify allosteric hot 
spots on protein surfaces [136,137]. Communication pathways predicted by SCA were used to find allosteric hot spots in dihydrofolate reductase (DHFR), and a chimeric protein was created by inserting a light-sensitive domain into DHFR at a predicted allosteric site, thereby obtaining an enzyme that can be regulated by light [84]. As a continuation of this experiment, it was shown by the same method that the set of all allosteric hot spots is almost identical to the set of surface sites connected to network defined by SCA, and a similar conclusion was made about a PDZ domain [85]. These findings also give an insight into how new sites for allosteric regulation may naturally evolve.

\subsection{Limitations of Protein Structure Networks for the Study of Allosteric Communication}

Studying allosteric communication by network analysis of protein structure graphs is a powerful approach based on an intuitive concept, and has yielded plausible and occasionally, experimentally validated results. However, it is not without limitations.

As we have seen, there are many ways of defining intraprotein networks, and not all methods give the same result. An MD based study using restraints from NMR experiments showed that the network obtained by mapping structural changes differs from that obtained from dynamical changes, and both are different from the co-evolving network obtained by SCA (although the overlap between the SCA and the dynamical network is larger) [138]. The network obtained by mapping torsion angle correlations is also different from that obtained from position correlations [110]. The hubs in a network obtained from Lennard-Jones energies tend to be located in the protein core, while those defined in the network based on full interaction energies tend to be at the surface [46].

A network constructed from a single, static structure cannot account for conformational changes. Communication pathways may not always pre-exist or may only be present in a scarcely populated subset of the native ensemble, thus easily evading detection even via ensemble-based methods. It was shown that the full communication path only gets assembled in Met-tRNA synthase when both substrates are bound [59]. Methods based on MD simulations yield networks reflecting different time scales of events, from the picosecond [126] to the tens of nanoseconds [110] range. In an MD study based on torsion angles, correlations between distant side chains were seen without a correlated chain of residues between them [110]. In this case, the correlation is probably mediated by events on a faster time scale that is not captured by the method.

Communication pathways built from residue-residue contact-based protein structure networks often lack a true physical basis (with the exception of elastic networks). Different types of perturbations may activate different communication pathways within a protein; e.g. a targeted, strong perturbation elicited by ligand binding may get propagated differently than thermal noise from the solvent [58]. Protein structure networks often do not take into account the differences in these perturbation types.

Most network-based methods to reveal communication pathways do not take side chain rotations into account, even though these have been shown to be involved in allosteric communication via rotamer population shifts $[89,110,138,139]$. Side-chain rotations generate their own network, which is impossible to map out from a static structure [140]. Many methods only use C $\alpha$ coordinates, although it has been shown that side chains should be included for best results [70].

All intra-protein network construction methods consider residues as nodes in the network. Although this is an obvious choice, residues have widely different sizes and physicochemical properties, which may bias the results of the analysis. For example, hubs are very often aromatic residues [57], which is at least in part due to their bulkiness [40]. In fact, residue types have different network properties due to their physico-chemical differences $[141,142]$. It was shown that a graph with chemical groups (groups of chemically similar atoms) as nodes is more suitable for the analysis of MD simulations than residue-based graphs [143].

Allostery itself may occur by a number of mechanisms, involving large or small or no conformational change, driven by enthalpy (structure), entropy (dynamics) or both [33], and the time scale of the allosteric change may also vary over a wide range. The protein may be highly modular or may consist of only a single, rigid domain. Ideally, the choice of method to describe communication pathways should depend on the particular protein, as well as the type and time scale of the allosteric change under study.

Even though network construction methods will always yield some communication network, allosteric 'information transmission' may in some cases not involve any particular pathway at all, as suggested by the ensemble view of allostery [144]. This may typically be the case for proteins where disordered regions or domains optimize allosteric coupling $[45,144]$, or where significant segments of the protein structure are extremely rigid $[1,45]$. Network-based methods to reveal allosteric pathways may have difficulties with handling significant disorder (i.e. extreme flexibility, plasticity) or extreme rigidity.

Finally, intra-protein networks usually do not include solvent molecules, even though they may be part of the allosteric pathway. It has been shown that water molecules at the interface between the subunits of hemoglobin carry a large part of the energy and are probably involved in allosteric communication [145].

Future research will probably yield more advanced methods that will surmount some of the weaknesses of existing methods. Despite the limitations, the findings of many network-based analyses of allostery have been supported by experiments, and the network view of proteins offers a useful framework for the discussion of allosteric processes.

\section{PROPAGATION OF SIGNALS IN CELLULAR NETWORKS}

The propagation of allosteric signals is not limited to single protein chains. The classical models of allostery describe allosteric effects in oligomeric proteins [23,24]. Network models of allosteric signal propagation have been applied to multimeric protein complexes [49-52]. Many of the examples of the preceding sections were also protein complexes. 
Cellular function can be described in terms of cellular networks such as protein-protein interaction networks, signal transduction networks, gene transcription networks, metabolic networks, etc. $[1,146,147]$. Evolution has optimized the cellular machinery to rapidly respond to changing conditions by the use of modular functional organization and large multimolecular assemblies. The binding of an allosteric effector to one protein may induce conformational or dynamic changes in adjacent proteins. The propagation of conformational changes is usually anisotropic and traverses across a pathway, thereby facilitating signal transduction over large distances (hundreds or thousands of angstroms). Thus, binding to a protein may elicit a limited, specific, and distant functional change in the network $[15,33,115,148]$.

A prime example of such functioning is the gigantic Mediator complex, which relays signals from specific DNA regulatory elements to initiate gene-specific transcription hundreds of angstroms away [149,150]. However, longrange signaling does not necessarily require a giant complex, since the signal can also propagate in a stepwise manner, where only two nodes are involved in each signal transmission step. As an example of specific propagation of longrange changes, Maslov and Ispolatov [151] used the law of mass action to calculate the effect of a two-fold increase in the expression of a single protein on the free concentration of other proteins in the yeast interactome. Despite of an exponential decay of changes, there were a few highly selective pathways where concentration changes propagated to a larger distance [151]. The perturbation dynamics of signaling networks was extensively analyzed including $~ 10,000$ phosphorylation events in an experimental study of yeast cells [152]. The size of the human interactome has been estimated to have 650,000 interactions [153]. Though several datasets have been published in the last decade [154-157], we are still a long way from deciphering the full complexity of the human interactome. Human signaling networks extend this complexity by the inclusion of directed and conditional interactions, as well as microRNAs [1].

The number of possible regulatory combinations for a given gene increases dramatically with an increase in input complexity and network size. For example, with 100 genes and 3 inputs per gene, there are about a million input combinations for each gene in the network, resulting in $10^{600}$ different network wiring diagrams [158]. Systems-level molecular networks have a 100-fold larger size. Estimates of the number of possible states of the yeast interactome range from $10^{7,200}$ to $10^{79,000,000,000}$ [159], which are all unimaginably high numbers. The number of possible states of the human interactome, which is an order of magnitude larger, must be even higher. At this level of system complexity, current descriptions of network dynamics contain several simplifications, e.g. they neglect node-specific delays, differences in individual dissipation patterns, effects of water, or molecular crowding. Most importantly, most current network-level cellular signal transduction models do not take into account the highly anisotropic nature of the perturbation propagation inside protein structures [115]. Construction of atomic-level resolution protein-protein interaction and signaling networks, with interacting 3D protein structures bound or docked at their experimentally shown or predicted binding sites, will be a major step towards high-resolution signal transduction models to understand long-range allosteric action. This step will add a new dimension of information especially to protein-protein interaction networks, which at present mostly contain probability-type interactions lacking structural and signal propagation details. A few proteinprotein interaction networks containing 3D protein structures have already been assembled [160-163], providing initial steps towards this goal.

\section{ALLO-NETWORK DRUGS: EXTENSION OF THE CONCEPT OF ALLOSTERIC DRUGS TO CELLU- LAR NETWORKS}

Traditional, orthosteric drugs bind to active sites of enzymes. However, their selectivity is hard to ensure as proteins acting on the same substrates (e.g. protein kinases which all use ATP) have similar active sites. To circumvent this problem, a number of allosteric drugs have been developed, mainly for seven transmembrane receptors, GPCRs [11,14,164-167] (see also other papers of this issue). Because allosteric drugs bind to sites different than the active site, they can be more specific, and thus usually have fewer side effects. Furthermore, allosteric drugs allow fine modulation of function instead of the inhibition of the protein achieved by most orthosteric drugs.

The combination of the concepts that intra-protein allosteric communication can be described via protein structure networks and that cellular function can be understood in terms of protein-protein interaction and signaling networks inspired a novel suggestion for drug target discovery: allonetwork drugs (Fig. (1), [15]). In this concept, instead of targeting a malfunctioning protein directly, a different protein in the cellular network neighborhood is targeted by the allo-network drug. The concept urges that drug discovery should harness the long-distance allosteric signal transduction pathways created by evolution to extend the scope of drug discovery targets. In allo-network drug action, the binding of the drug triggers a pathway of conformational (or dynamic) changes over a segment of the protein-protein interaction or signaling network, finally reaching a target protein, where it may then, for example, enhance or inhibit another pathway of propagating conformational changes. Because pathways evolved by nature are limited and specific, allonetwork drugs have the potential to be highly selective and disease-specific. This approach may dramatically increase the number of target proteins that can be considered as drug targets.

Earlier works already pointed towards an allo-network type drug action, like the suggestion of inter-protein propagation of allosteric effects $[10,168]$ and the possible use of such an effect in drug design [7]. In fact, drugs that can be considered allo-network drugs already exist. Combination therapies and multi-target drugs combine multiple effects, often at places distant from the malfunctioning protein in the cellular network [2]. Examples from cancer drugs include BRAF and MEK combination therapy $[169,170]$ and rapamycin/FKBP12, an inhibitor of the mTORC1 complex [171,172]. Moreover, drug-target network studies revealed that in more than half of the established 922 drug-disease pairs, drugs do not target the actual disease-associated proteins, but bind to their $3^{\text {rd }}$ or $4^{\text {th }}$ neighbors. However, the 


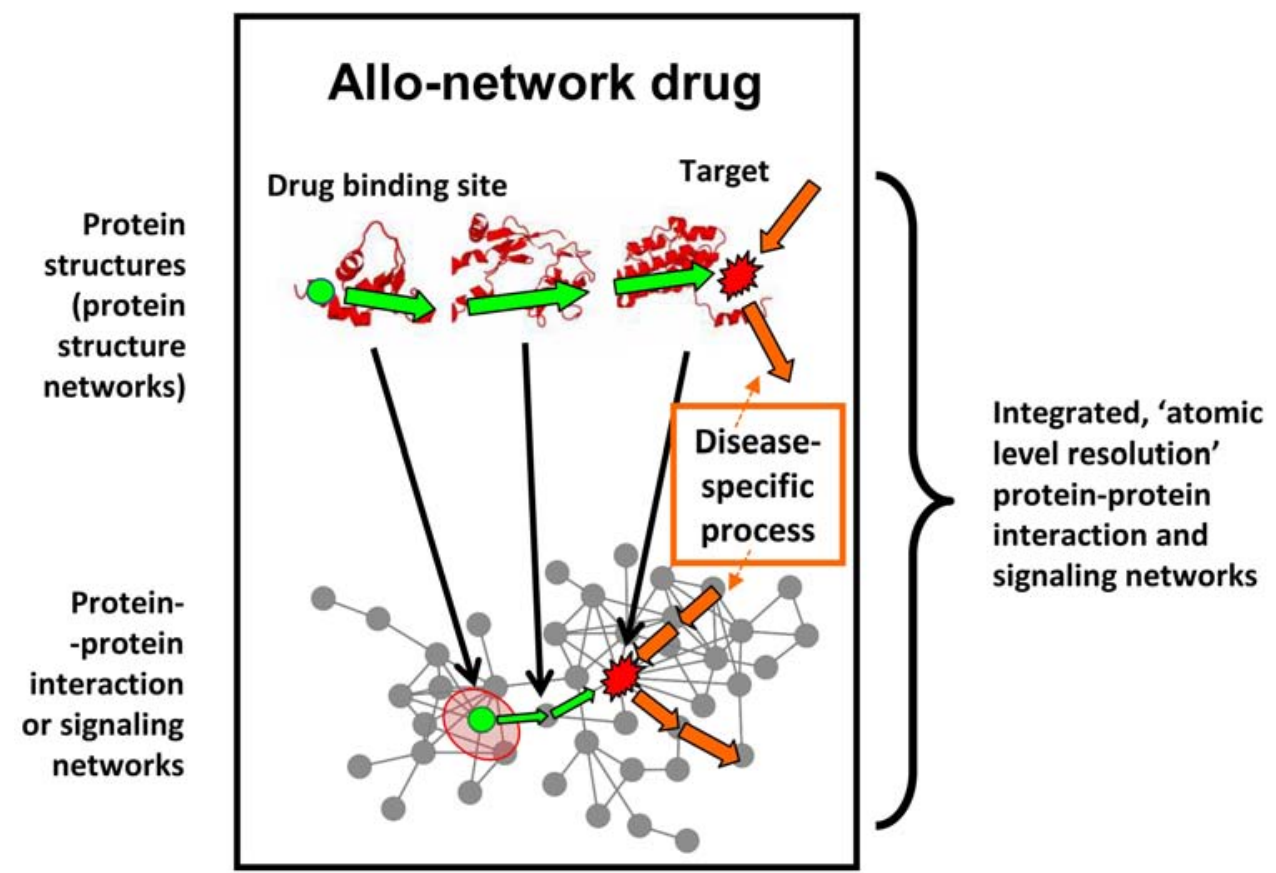

Fig. (1). Allo-network drugs. The top part of the figure illustrates the protein structures of the allo-network drug target containing the primary binding site (green circle), a 'transmission' protein, and the final target. The bottom part of figure illustrates the positions of the same 3 proteins in the human protein-protein interaction or signaling network. The red ellipse illustrates the 'action radius', i.e. the network perturbation induced by the primary target. In the top part, signal propagation (illustrated by the light green arrows) extends beyond the original drug binding protein and affects two neighboring proteins in the network via specific interactions. The pharmacologically active final target is marked by a red asterisk. Orange arrows illustrate an intracellular pathway of propagating conformational changes, which is disease-specific in case of successful allo-network drugs. Allo-network drugs allow indirect and specific targeting of key proteins by a primary attack on a 'silent' protein which is not involved in major cellular pathways. Targeting 'silent', 'by-stander' proteins, which specifically influence pharmacological targets, not only expands the current list of drug targets, but also causes much less side-effects and toxicity. (The color version of the figure is available in the electronic copy of the article).

distance between drug targets and disease-associated proteins was regarded as a sign of palliative drug action $[3,13]$, and the expansion of the concept of allosteric drug action to the interactome level has been formulated only recently [15].

Thinking in network terms, the action of drugs can be perceived as a network perturbation. The drug-induced attack either destroys the network of infectious or cancer cells, or shifts the pathophysiological network status back to normal [115,173-175]. Perturbation mediators in anti-infectious or anti-cancer therapies are often at cross-roads of cellular pathways. On the contrary, in other diseases such as diabetes or neurodegenerative diseases, efficient drug targets are not directly involved in major cellular pathways but indirectly influence them in a highly efficient manner [1]. Thus, the indirect but highly directed action of allo-network drugs can achieve specific, limited changes at the systems level, with fewer side-effects and lower toxicity than those of conventional drugs [15]. In agreement with this assumption, drugs with targets less than 3 steps (or more than 4 steps) from a disease-associated protein were suggested to have more sideeffects and to fail more often [176]. However, rational drug design proceeded in the opposite direction, identifying drug targets closer to disease-associated proteins than earlier [3]. The recently observed reversal of this trend may be more productive. Allo-network drugs point exactly to this direction.

\section{ALLO-NETWORK DRUGS AS SPECIFIC EFFEC- TORS OF DISEASE-AFFECTED HUMAN CELLS}

Human cells seem to have developed a larger complexity of their networks than other organisms. This is especially true for signaling networks, where major signaling pathways have all possible crosstalks in human cells, while the same is not at all true in C. elegans or in Drosophila [177]. The complexity of regulation also increased through additional binding factors, as, for example, apparent in the structure of the transcriptional Mediator mega-complex [149,178].

Not only the static network structure but network dynamics also increased in human cells. The variability of human protein-protein interactions is much larger than that seen in other interactomes. Besides single-nucleotide polymorphisms, alternative splicing, addition of $\mathrm{N}$ - or $\mathrm{C}$-terminal tags, partial proteolysis and other post-translational modifications (such as phosphorylation), as well as changes in protein expression patterns may dramatically re-configure protein complexes [179]. Moreover, the human interactome seems to have a higher proportion of 'sticky' proteins leading to more promiscuous interactions than the E. coli or $S$. cerevisiae interactomes [180]. As an additional factor of network dynamics, the human interactome is enriched with disordered proteins, causing dynamically fluctuating, 'fuzzy' interaction patterns $[45,181]$. 
The increased inter-pathway signaling, as well as the coupled large assemblies, all extend the propagation pathway repertoire of inter-molecular allosteric changes. Complex organization is helped by increased modularity, but increased variability and disordered proteins help to cross module boundaries and amplify intra- and inter-protein allosteric relays [148]. Thus, allo-network drug-like action occurs most where it is needed most: in human cells.

Promising allo-network drugs should interfere with disease-specific pathways $[1,15]$. Targeting disease-induced dynamical changes in molecular networks may be focused on transient interactions specific to disease. Thus, allonetwork drugs may also provide a novel solution to uncompetitive, 'interfacial' drug action [173,182,183].

Finally, current drugs usually inhibit protein-protein interactions [184]. Allo-network drugs may also trap a protein in its inactive state $[87,185]$. This way, the inter-molecular, long-range conformational change is prevented by the allonetwork drug. However, importantly, besides inhibition, allo-network drugs may stabilize, restore and/or activate a protein, its function, or one (or more) of its interactions [186].

\section{POSSIBLE METHODS TO IDENTIFY ALLO- NETWORK DRUG TARGETS}

As it is conceivable from Fig. (1), at the molecular network level, allo-network drug design needs to solve three closely related problems. 1.) An appropriate pharmacological target protein playing a crucial role in shifting the disease state of the cell back to normal should be found. 2.) An appropriate allo-network drug target protein should be found which is in the network neighborhood of the pharmacological target protein but plays no major role in cellular processes and therefore its direct manipulation has no major sideeffects. 3.) A communication channel should exist between the allo-network target of point 2 and the pharmacological target of point 1 , i.e. the changes of the allo-network target should selectively propagate towards the pharmacological target in the atomic-resolution network structure.

Since the above points 2 and 3 are related and set rather stringent requirements for the allo-network drug target, search procedures can be greatly facilitated by increasing the resolution of data on cellular networks (the interactome and/or the signaling network) to atomic or amino acid level. To obtain a map of a protein complex at atomic resolution, docking of 3D protein structures and the consequent connection of their protein structure networks are needed. A few protein-protein interaction networks containing 3D protein structures have already been assembled [160-163], providing initial steps towards this goal. These efforts may be extended by mapping the protein structures into low-resolution EM density maps [187]. Thus, allo-network drug targeting requires the integration of our knowledge on protein structures, molecular networks, and their dynamics, focusing particularly on disease-induced changes. The identification of promising drug targets requires a deep understanding of how the cellular networks (interactomes and signaling networks) work, along with detailed structural knowledge of the proteins and complexes involved. To map the cellular networks at the atomic resolution level, experimental structural and functional data need to be combined with modeling tools to predict which proteins interact and how [188]. Construction of these atomic level cellular networks should also take into account that proteins in different conformations may interact with different partners and different drug molecules; therefore, dynamic protein-protein interaction [161] and signaling networks, as well as conformation-dependent drug-target networks [189] have to be used.

We list a few possible methods to define allo-network drug target sites and allo-network pathways to the pharmacological targets in cellular networks at atomic level resolution (Fig. (2)).

- Central residues play a key role in the transmission of allosteric changes $[65,71,95,97,101,102,127,135,190$ 193]. We may use a number of centrality measures [194], including perturbation-based or game-theoretical assumptions $[115,195]$, to find the level of importance of proteins and pathways in interactomes and signaling networks, and important amino acids in their extensions to atomic level resolution [69].

- At both the molecular network level and its extension to atomic level resolution, we may extract network hierarchy $[69,196-201]$ to assess the importance of various nodes (proteins and/or amino acids).

- We may find nodes or edges controlling the network by the application of recently published methods [201-207].

- Network-based analysis of perturbation propagation is a fruitful method to identify intra-protein allosteric pathways $[21,44,45,59-61,71,93,97,102,111,127,208]$. A successful candidate for the inter-protein allosteric pathways involved in allo-network drug action disturbs network perturbations specific to a disease state of the cell at a site distant from the original drug-binding site. Perturbation analysis $[115,195]$ applied to the atomic-level-resolution interactome in combination with disease-specific protein expression patterns may help the identification of such allo-network drug targets.

- A general strategy for the identification of allosteric sites may involve finding large correlated motions between binding sites. This can reveal which residue-residue correlated motions change upon ligand binding, and thus can suggest new allosteric sites [209] even in integrated networks of protein mega-complexes.

- Reverse engineering methods [158] allow us to discriminate between 'high-intensity' and 'low-intensity' communication pathways both in molecular and atomic level networks, and thus may provide a larger safety margin for allo-network drugs.

- Combination of evolutionary conservation data has proven to be an efficient predictor of intra-protein signaling pathways [60,85,210-212]. Similar approaches may be extended to protein neighborhoods helping to find starting sites for allo-network drug action.

- Disease-associated single-nucleotide polymorphisms (SNPs; [213]) and/or mutations [214] may often be part of the propagation pathways of allosteric effects. Inframe mutations are enriched in interaction interfaces [214], and provide an interesting dataset that could be 


\section{Methods to find allo-network drugs}

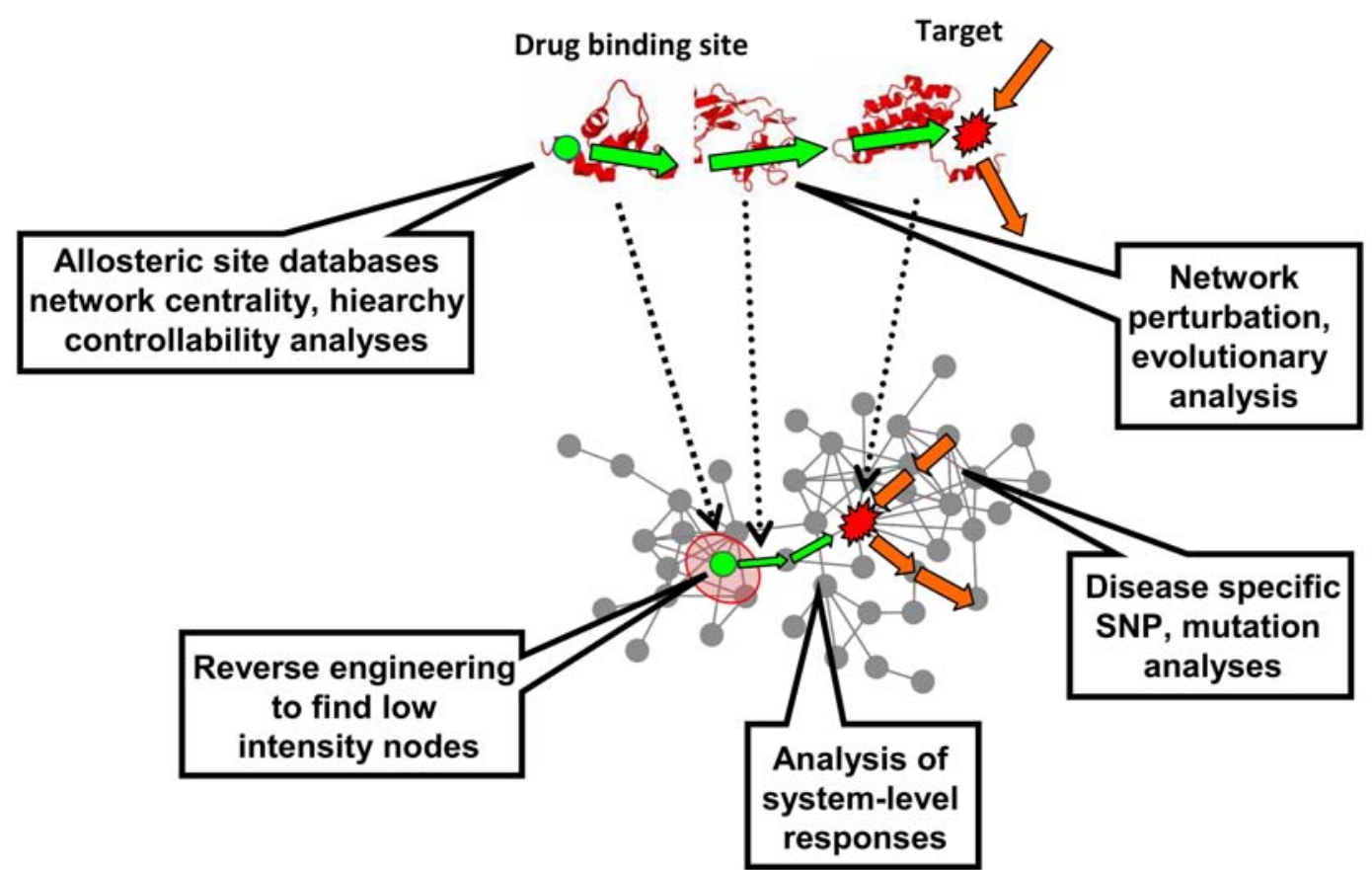

Fig. (2). Methods to find allo-network drugs. All middle segments and notations of the figure are the same as those explained in the legend of Fig. (1). (Top part: protein structures; green circle: allo-network drug binding site; light green arrows: signal propagation; red asterisk: pharmacologically active target; orange arrows: disease-specific pathway; bottom part: protein-protein interaction or signaling networks; red ellipse: 'action radius'.) Boxes highlight the various network- and system-based methods helping the identification of allo-network drugs. (The color version of the figure is available in the electronic copy of the article).

used to predict the existence of allo-network drug binding sites.

We also give a few additional hints and considerations for successful allo-network drug finding.

- Databases of allosteric binding sites (http://mdl.shsmu.edu.cn/ASD [215]) help the identification of possible sites of allo-network drug action. However, allo-network drugs may also bind to sites not used by natural ligands, and inter-molecular allosteric effects may use other sites beyond those involved in intramolecular allosterism.

- Drugs may fail when the cell bypasses drug action via a parallel pathway. Therefore, it is important to obtain a complete view of the network and to identify possible alternative pathways [216].

- Because allo-network drugs have systems-level effects, cell-based assays can be used to find such compounds, similar to classical allosteric drugs. A number of experimental methods can be used to find and analyze cellular system-level responses. This may involve extensive pathway profiling and high-throughput RNAi screening [217].

Despite the considerable challenges, detailed structural and functional knowledge and understanding of the pathways and information flow in the cellular networks at atomic level resolution will help to circumvent the long trial-and- error process that was followed by evolution to develop allonetwork action.

\section{CONCLUSION AND PERSPECTIVES}

We predict that allo-network drug related systems-level and network analysis methods will develop to 'rational allonetwork drug design' protocols in the coming years, and hope that these efforts will result in novel drugs with greater selectivity and effectiveness. Allo-network drugs may involve drug targets that are not related at all to usual drug target families.

However, the development of rational allo-network drug design protocols requires 1.) a much more detailed understanding of cellular network structure and dynamics at the atomic resolution level including forward and backward loops; 2.) understanding allosteric signal propagation in networks and finding the key points where this dynamics can be influenced in an indirect but efficient and selective manner from a larger distance [31]; 3.) incorporation of diseasespecific systems-level data and data on dynamics and network specificities [216].

Despite the considerable challenges, the rapidity of the increase in systems-level data on healthy and diseased cells and the remarkable progress of network analysis methodology in the last few years gives us strong hope that the rational development of allo-network drugs will be a widely pursued option of the drug industry in a few years. 


\section{CONFLICT OF INTEREST}

The author(s) confirm that this article content has no conflict of interest.

\section{ACKNOWLEDGEMENTS}

Work in the authors' laboratory was supported by research grants from the Hungarian National Science Foundation (OTKA K83314, K105415), by the EU (TÁMOP4.2.2/B-10/1-2010-0013). This project has been funded, in part, with federal funds from the NCI, NIH, under contract HHSN261200800001E. This research was supported, in part, by the Intramural Research Program of the NIH, National Cancer Institute, Center for Cancer Research. The content of this publication does not necessarily reflect the views or policies of the Department of Health and Human Services, nor does mention of trade names, commercial products, or organizations imply endorsement by the U.S. Government.

\section{REFERENCES}

[1] Csermely, P.; Korcsmaros, T.; Kiss, H. J.; London, G.; Nussinov, R. Structure and dynamics of biological networks: a novel paradigm of drug discovery. A comprehensive review. Pharmacol Therap 2013, in press.

[2] Csermely, P.; Agoston, V.; Pongor, S. The efficiency of multitarget drugs: the network approach might help drug design. Trends Pharmacol Sci 2005, 26, 178-182

[3] Yildirim, M. A.; Goh, K. I.; Cusick, M. E.; Barabasi, A. L.; Vidal, M. Drug-target network. Nat Biotechnol 2007, 25, 1119-1126.

[4] Pawson, T.; Linding, R. Network medicine. FEBS Lett 2008, 582, 1266-1270.

[5] Cui, Q.; Karplus, M. Allostery and cooperativity revisited. Protein Sci 2008, 17, 1295-1307.

[6] Hopkins, A. L. Network pharmacology: the next paradigm in drug discovery. Nat Chem Biol 2008, 4, 682-690.

[7] Schadt, E. E.; Friend, S. H.; Shaywitz, D. A. A network view of disease and compound screening. Nat Rev Drug Discov 2009, 8, 286-295

[8] Berger, S. I.; Iyengar, R. Network analyses in systems pharmacology. Bioinformatics 2009, 25, 2466-2472.

[9] Pujol, A.; Mosca, R.; Farres, J.; Aloy, P. Unveiling the role of network and systems biology in drug discovery. Trends Pharmacol Sci 2010, 31, 115-123.

[10] Fliri, A. F.; Loging, W. T.; Volkmann, R. A. Cause-effect relationships in medicine: a protein network perspective. Trends Pharmacol Sci 2010, 31, 547-555.

[11] Digby, G. J.; Conn, P. J.; Lindsley, C. W. Orthosteric- and allosteric-induced ligand-directed trafficking at GPCRs. Curr Opin Drug Discov Devel 2010, 13, 587-594.

[12] Baggs, J. E.; Hughes, M. E.; Hogenesch, J. B. The network as the target. Wiley Interdiscip Rev Syst Biol Med 2010, 2, 127-133.

[13] Barabasi, A. L.; Gulbahce, N.; Loscalzo, J. Network medicine: a network-based approach to human disease. Nat Rev Genet 2011, $12,56-68$

[14] Maksay, G. Allostery in pharmacology: thermodynamics, evolution and design. Prog Biophys Mol Biol 2011, 106, 463-473.

[15] Nussinov, R.; Tsai, C. J.; Csermely, P. Allo-network drugs: harnessing allostery in cellular networks. Trends Pharmacol Sci 2011, 32, 686-693.

[16] Fischer, E. Einfluss der Configuration auf die Wirkung der Enzyme. Ber Dtsch Chem Ges 1894, 27, 2984-2993.

[17] Straub, F. B.; Szabolcsi, G., On the dynamics aspects of protein structure. In Molecular biology: problems and perspectives., Braunstein, A. E., Ed. Nauka: Moscow, 1964; pp 182-187.

[18] Zavodszky, P.; Abaturov, L. V.; Varshavsky, Y. M. Structure of glyceraldehyde-3-phosphate dehydrogenase and its alteration by coenzyme binding. Acta Biochim Biophys Acad Sci Hung 1966, 1, 389-403.

[19] Tsai, C. J.; Kumar, S.; Ma, B.; Nussinov, R. Folding funnels, binding funnels, and protein function. Protein Sci 1999, 8, 11811190 .
[20] Koshland, D. E. Application of a Theory of Enzyme Specificity to Protein Synthesis. Proc Natl Acad Sci U S A 1958, 44, 98-104.

[21] Goodey, N. M.; Benkovic, S. J. Allosteric regulation and catalysis emerge via a common route. Nat Chem Biol 2008, 4, 474-482.

[22] Csermely, P.; Palotai, R.; Nussinov, R. Induced fit, conformational selection and independent dynamic segments: an extended view of binding events. Trends Biochem Sci 2010, 35, 539-546.

[23] Monod, J.; Wyman, J.; Changeux, J. P. On the nature of allosteric transitions: a plausible model. J Mol Biol 1965, 12, 88-118.

[24] Koshland, D. E., Jr.; Nemethy, G.; Filmer, D. Comparison of experimental binding data and theoretical models in proteins containing subunits. Biochemistry 1966, 5, 365-385.

[25] Whitley, M. J.; Lee, A. L. Frameworks for understanding longrange intra-protein communication. Curr Protein Pept Sci 2009, 10, 116-127.

[26] Weber, G. Ligand binding and internal equilibria in proteins. Biochemistry 1972, 11, 864-878.

[27] Changeux, J. P.; Edelstein, S. Conformational selection or induced fit? 50 years of debate resolved. F1000 Biol Rep 2011, 3, 19.

[28] Zhuravlev, P. I.; Papoian, G. A. Protein functional landscapes, dynamics, allostery: a tortuous path towards a universal theoretical framework. $Q$ Rev Biophys 2010, 43, 295-332.

[29] Gunasekaran, K.; Ma, B.; Nussinov, R. Is allostery an intrinsic property of all dynamic proteins? Proteins 2004, 57, 433-443.

[30] Cooper, A.; Dryden, D. T. Allostery without conformational change. A plausible model. Eur Biophys J 1984, 11, 103-109.

[31] Tsai, C. J.; del Sol, A.; Nussinov, R. Allostery: absence of a change in shape does not imply that allostery is not at play. $J$ Mol Biol 2008, 378, 1-11.

[32] Popovych, N.; Sun, S.; Ebright, R. H.; Kalodimos, C. G. Dynamically driven protein allostery. Nat Struct Mol Biol 2006, 13 , 831-838.

[33] Tsai, C. J.; Del Sol, A.; Nussinov, R. Protein allostery, signal transmission and dynamics: a classification scheme of allosteric mechanisms. Mol Biosyst 2009, 5, 207-216.

[34] Hilser, V. J.; Wrabl, J. O.; Motlagh, H. N. Structural and energetic basis of allostery. Annu Rev Biophys 2012, 41, 585-609.

[35] Bagler, G.; Sinha, S. Network properties of protein structures. Physica A 2005, 346, 27-33.

[36] Kundu, S. Amino acid network within protein. Physica A 2005, 346, 104-109.

[37] Kannan, N.; Vishveshwara, S. Identification of side-chain clusters in protein structures by a graph spectral method. J Mol Biol 1999, 292, 441-464.

[38] Greene, L. H.; Higman, V. A. Uncovering network systems within protein structures. J Mol Biol 2003, 334, 781-791.

[39] Atilgan, A. R.; Akan, P.; Baysal, C. Small-world communication of residues and significance for protein dynamics. Biophys $J \mathbf{2 0 0 4}, 86$, 85-91.

[40] Brinda, K. V.; Vishveshwara, S. A network representation of protein structures: implications for protein stability. Biophys $J$ 2005, 89, 4159-4170.

[41] Aftabuddin, M.; Kundu, S. Hydrophobic, hydrophilic, and charged amino acid networks within protein. Biophys $J$ 2007, 93, 225-231

[42] Bode, C.; Kovacs, I. A.; Szalay, M. S.; Palotai, R.; Korcsmaros, T.; Csermely, P. Network analysis of protein dynamics. FEBS Lett 2007, 581, 2776-2782.

[43] Krishnan, A.; Zbilut, J. P.; Tomita, M.; Giuliani, A. Proteins as networks: usefulness of graph theory in protein science. Curr Protein Pept Sci 2008, 9, 28-38.

[44] Vishveshwara, S.; Ghosh, A.; Hansia, P. Intra and inter-molecular communications through protein structure network. Curr Protein Pept Sci 2009, 10, 146-160.

[45] Csermely, P.; Sandhu, K. S.; Hazai, E.; Hoksza, Z.; Kiss, H. J.; Miozzo, F.; Veres, D. V.; Piazza, F.; Nussinov, R. Disordered proteins and network disorder in network descriptions of protein structure, dynamics and function: hypotheses and a comprehensive review. Curr Protein Pept Sci 2012, 13, 19-33.

[46] Vijayabaskar, M. S.; Vishveshwara, S. Interaction energy based protein structure networks. Biophys $J$ 2010, 99, 3704-3715.

[47] Amitai, G.; Shemesh, A.; Sitbon, E.; Shklar, M.; Netanely, D.; Venger, I.; Pietrokovski, S. Network analysis of protein structures identifies functional residues. J Mol Biol 2004, 344, 1135-1146.

[48] Csermely, P. Creative elements: network-based predictions of active centres in proteins and cellular and social networks. Trends Biochem Sci 2008, 33, 569-576. 
[49] Kannan, N.; Chander, P.; Ghosh, P.; Vishveshwara, S.; Chatterji, D. Stabilizing interactions in the dimer interface of alpha-subunit in Escherichia coli RNA polymerase: a graph spectral and point mutation study. Protein Sci 2001, 10, 46-54.

[50] del Sol, A.; O'Meara, P. Small-world network approach to identify key residues in protein-protein interaction. Proteins 2005, 58, 672682.

[51] Brinda, K. V.; Surolia, A.; Vishveshwara, S. Insights into the quaternary association of proteins through structure graphs: a case study of lectins. Biochem J 2005, 391, 1-15.

[52] Brinda, K. V.; Vishveshwara, S. Oligomeric protein structure networks: insights into protein-protein interactions. $B M C$ Bioinformatics 2005, 6, 296.

[53] Vendruscolo, M.; Dokholyan, N. V.; Paci, E.; Karplus, M. Smallworld view of the amino acids that play a key role in protein folding. Phys Rev E Stat Nonlin Soft Matter Phys 2002, 65, 061910

[54] Ghosh, A.; Brinda, K. V.; Vishveshwara, S. Dynamics of lysozyme structure network: probing the process of unfolding. Biophys $J$ 2007, 92, 2523-2535.

[55] Bagler, G.; Sinha, S. Assortative mixing in Protein Contact Networks and protein folding kinetics. Bioinformatics 2007, 23, 1760-1767.

[56] Jiao, X.; Chang, S.; Li, C. H.; Chen, W. Z.; Wang, C. X. Construction and application of the weighted amino acid network based on energy. Phys Rev E Stat Nonlin Soft Matter Phys 2007, $75,051903$.

[57] del Sol, A.; Fujihashi, H.; Amoros, D.; Nussinov, R. Residues crucial for maintaining short paths in network communication mediate signaling in proteins. Mol Syst Biol 2006, 2, 2006.0019.

[58] Atilgan, A. R.; Turgut, D.; Atilgan, C. Screened nonbonded interactions in native proteins manipulate optimal paths for robust residue communication. Biophys $J$ 2007, 92, 3052-3062.

[59] Ghosh, A.; Vishveshwara, S. A study of communication pathways in methionyl- tRNA synthetase by molecular dynamics simulations and structure network analysis. Proc Natl Acad Sci U S A 2007, 104, 15711-15716.

[60] Tang, S.; Liao, J. C.; Dunn, A. R.; Altman, R. B.; Spudich, J. A.; Schmidt, J. P. Predicting allosteric communication in myosin via a pathway of conserved residues. J Mol Biol 2007, 373, 1361-1373.

[61] Sethi, A.; Eargle, J.; Black, A. A.; Luthey-Schulten, Z. Dynamical networks in tRNA:protein complexes. Proc Natl Acad Sci U S A 2009, 106, 6620-6625.

[62] Fanelli, F.; Felline, A. Dimerization and ligand binding affect the structure network of $\mathrm{A}(2 \mathrm{~A})$ adenosine receptor. Biochim Biophys Acta 2011, $1808,1256-1266$.

[63] Angelova, K.; Felline, A.; Lee, M.; Patel, M.; Puett, D.; Fanelli, F. Conserved amino acids participate in the structure networks deputed to intramolecular communication in the lutropin receptor. Cell Mol Life Sci 2011, 68, 1227-1239.

[64] Ghosh, A.; Sakaguchi, R.; Liu, C.; Vishveshwara, S.; Hou, Y. M. Allosteric communication in cysteinyl tRNA synthetase: a network of direct and indirect readout. $J$ Biol Chem 2011, 286, 3772137731 .

[65] Pandini, A.; Fornili, A.; Fraternali, F.; Kleinjung, J. Detection of allosteric signal transmission by information-theoretic analysis of protein dynamics. FASEB $\mathrm{J} \mathbf{2 0 1 2}, 26,868-881$.

[66] Del Sol, A.; Arauzo-Bravo, M. J.; Amoros, D.; Nussinov, R. Modular architecture of protein structures and allosteric communications: potential implications for signaling proteins and regulatory linkages. Genome Biol 2007, 8, R92.

[67] Delvenne, J. C.; Yaliraki, S. N.; Barahona, M. Stability of graph communities across time scales. Proc Natl Acad Sci U S A 2010, $107,12755-12760$

[68] Delmotte, A.; Tate, E. W.; Yaliraki, S. N.; Barahona, M. Protein multi-scale organization through graph partitioning and robustness analysis: application to the myosin-myosin light chain interaction. Phys Biol 2011, 8, 055010.

[69] Szalay-Beko, M.; Palotai, R.; Szappanos, B.; Kovacs, I. A.; Papp, B.; Csermely, P. ModuLand plug-in for Cytoscape: determination of hierarchical layers of overlapping network modules and community centrality. Bioinformatics 2012, 28, 2202-2204.

[70] VanWart, A. T.; Eargle, J.; Luthey-Schulten, Z.; Amaro, R. E. Exploring residue component contributions to dynamical network models of allostery. J Chem Theory Comput 2012, 8, 2949-2961.
[71] Chennubhotla, C.; Bahar, I. Markov propagation of allosteric effects in biomolecular systems: application to GroEL-GroES. Mol Syst Biol 2006, 2, 36

[72] Lockless, S. W.; Ranganathan, R. Evolutionarily conserved pathways of energetic connectivity in protein families. Science 1999, 286, 295-299.

[73] Kass, I.; Horovitz, A. Mapping pathways of allosteric communication in GroEL by analysis of correlated mutations. Proteins 2002, 48, 611-617.

[74] Suel, G. M.; Lockless, S. W.; Wall, M. A.; Ranganathan, R. Evolutionarily conserved networks of residues mediate allosteric communication in proteins. Nat Struct Biol 2003, 10, 59-69.

[75] Hatley, M. E.; Lockless, S. W.; Gibson, S. K.; Gilman, A. G.; Ranganathan, R. Allosteric determinants in guanine nucleotidebinding proteins. Proc Natl Acad Sci U S A 2003, 100, 1444514450.

[76] Ferguson, A. D.; Amezcua, C. A.; Halabi, N. M.; Chelliah, Y.; Rosen, M. K.; Ranganathan, R.; Deisenhofer, J. Signal transduction pathway of TonB-dependent transporters. Proc Natl Acad Sci U S A 2007, 104, 513-518.

[77] McLaughlin, R. N., Jr.; Poelwijk, F. J.; Raman, A.; Gosal, W. S.; Ranganathan, R. The spatial architecture of protein function and adaptation. Nature 2012, 491, 138-142.

[78] Fuentes, E. J.; Der, C. J.; Lee, A. L. Ligand-dependent dynamics and intramolecular signaling in a PDZ domain. J Mol Biol 2004, $335,1105-1115$.

[79] Fodor, A. A.; Aldrich, R. W. On evolutionary conservation of thermodynamic coupling in proteins. J Biol Chem 2004, 279, 19046-19050.

[80] Chi, C. N.; Elfstrom, L.; Shi, Y.; Snall, T.; Engstrom, A.; Jemth, P. Reassessing a sparse energetic network within a single protein domain. Proc Natl Acad Sci U S A 2008, 105, 4679-4684.

[81] Liu, Z.; Chen, J.; Thirumalai, D. On the accuracy of inferring energetic coupling between distant sites in protein families from evolutionary imprints: illustrations using lattice model. Proteins 2009, 77, 823-831.

[82] Chen, J.; Dima, R. I.; Thirumalai, D. Allosteric communication in dihydrofolate reductase: signaling network and pathways for closed to occluded transition and back. J Mol Biol 2007, 374, 250-266.

[83] Sayar, K.; Ugur, O.; Liu, T.; Hilser, V. J.; Onaran, O. Exploring allosteric coupling in the alpha-subunit of heterotrimeric $\mathrm{G}$ protein using evolutionary and ensemble-based approaches. BMC Struct Biol 2008, 8, 23

[84] Lee, J.; Natarajan, M.; Nashine, V. C.; Socolich, M.; Vo, T.; Russ, W. P.; Benkovic, S. J.; Ranganathan, R. Surface sites for engineering allosteric control in proteins. Science 2008, 322, 438442.

[85] Reynolds, K. A.; McLaughlin, R. N.; Ranganathan, R. Hot spots for allosteric regulation on protein surfaces. Cell 2011, 147, 15641575 .

[86] Sadovsky, E.; Yifrach, O. Principles underlying energetic coupling along an allosteric communication trajectory of a voltage-activated K+ channel. Proc Natl Acad Sci U S A 2007, 104, 19813-19818.

[87] Lee, G. M.; Craik, C. S. Trapping moving targets with small molecules. Science 2009, 324, 213-215.

[88] Zhuravleva, A.; Gierasch, L. M. Allosteric signal transmission in the nucleotide-binding domain of $70-\mathrm{kDa}$ heat shock protein (Hsp70) molecular chaperones. Proc Natl Acad Sci U S A 2011, 108, 6987-6992.

[89] Clarkson, M. W.; Gilmore, S. A.; Edgell, M. H.; Lee, A. L. Dynamic coupling and allosteric behavior in a nonallosteric protein. Biochemistry 2006, 45, 7693-7699.

[90] Selvaratnam, R.; Chowdhury, S.; VanSchouwen, B.; Melacini, G. Mapping allostery through the covariance analysis of NMR chemical shifts. Proc Natl Acad Sci U S A 2011, 108, 6133-6138.

[91] Selvaratnam, R.; Mazhab-Jafari, M. T.; Das, R.; Melacini, G. The Auto-Inhibitory Role of the EPAC Hinge Helix as Mapped by NMR. PLoS One 2012, 7, e48707.

[92] del Sol, A.; Tsai, C. J.; Ma, B.; Nussinov, R. The origin of allosteric functional modulation: multiple pre-existing pathways. Structure 2009, 17, 1042-1050.

[93] Daily, M. D.; Upadhyaya, T. J.; Gray, J. J. Contact rearrangements form coupled networks from local motions in allosteric proteins. Proteins 2008, 71, 455-466. 
[94] Daily, M. D.; Gray, J. J. Allosteric communication occurs via networks of tertiary and quaternary motions in proteins. PLoS Comput Biol 2009, 5, e1000293.

[95] Chennubhotla, C.; Yang, Z.; Bahar, I. Coupling between global dynamics and signal transduction pathways: a mechanism of allostery for chaperonin GroEL. Mol Biosyst 2008, 4, 287-292.

[96] Shrivastava, I.; LaLonde, J. M. Fluctuation dynamics analysis of gp120 envelope protein reveals a topologically based communication network. Proteins 2010, 78, 2935-2949.

[97] Park, K.; Kim, D. Modeling allosteric signal propagation using protein structure networks. BMC Bioinformatics 2011, 12 Suppl 1, S23.

[98] Chennubhotla, C.; Bahar, I. Signal propagation in proteins and relation to equilibrium fluctuations. PLoS Comput Biol 2007, 3, 1716-1726.

[99] Bahar, I.; Rader, A. J. Coarse-grained normal mode analysis in structural biology. Curr Opin Struct Biol 2005, 15, 586-592.

[100] Zheng, W.; Brooks, B. R.; Thirumalai, D. Low-frequency normal modes that describe allosteric transitions in biological nanomachines are robust to sequence variations. Proc Natl Acad Sci U S A 2006, 103, 7664-7669.

[101] Zheng, W.; Brooks, B. R.; Thirumalai, D. Allosteric transitions in the chaperonin GroEL are captured by a dominant normal mode that is most robust to sequence variations. Biophys $J \mathbf{2 0 0 7}, 93$, 2289-2299.

[102] Tehver, R.; Chen, J.; Thirumalai, D. Allostery wiring diagrams in the transitions that drive the GroEL reaction cycle. $J$ Mol Biol 2009, 387, 390-406.

[103] Atilgan, C.; Atilgan, A. R. Perturbation-response scanning reveals ligand entry-exit mechanisms of ferric binding protein. PLoS Comput Biol 2009, 5, e1000544.

[104] Martin, D. R.; Matyushov, D. V. Solvated dissipative electroelastic network model of hydrated proteins. J Chem Phys 2012, 165101.

[105] Nechushtai, R.; Lammert, H.; Michaeli, D.; Eisenberg-Domovich, Y.; Zuris, J. A.; Luca, M. A.; Capraro, D. T.; Fish, A.; Shimshon, O.; Roy, M.; Schug, A.; Whitford, P. C.; Livnah, O.; Onuchic, J. N.; Jennings, P. A. Allostery in the ferredoxin protein motif does not involve a conformational switch. Proc Natl Acad Sci US A 2011, 108, 2240-2245.

[106] Morra, G.; Verkhivker, G.; Colombo, G. Modeling signal propagation mechanisms and ligand-based conformational dynamics of the Hsp90 molecular chaperone full-length dimer. PLoS Comput Biol 2009, 5, e1000323.

[107] Dixit, A.; Verkhivker, G. M. Computational modeling of allosteric communication reveals organizing principles of mutation-induced signaling in ABL and EGFR kinases. PLoS Comput Biol 2011, 7, e1002179.

[108] Kong, Y.; Karplus, M. The signaling pathway of rhodopsin. Structure 2007, 15, 611-623.

[109] Kong, Y.; Karplus, M. Signaling pathways of PDZ2 domain: a molecular dynamics interaction correlation analysis. Proteins 2009, $74,145-154$

[110] McClendon, C. L.; Friedland, G.; Mobley, D. L.; Amirkhani, H.; Jacobson, M. P. Quantifying Correlations Between Allosteric Sites in Thermodynamic Ensembles. J Chem Theory Comput 2009, 5, 2486-2502.

[111] Pan, H.; Lee, J. C.; Hilser, V. J. Binding sites in Escherichia coli dihydrofolate reductase communicate by modulating the conformational ensemble. Proc Natl Acad Sci U S A 2000, 97, 12020-12025.

[112] Liu, T.; Whitten, S. T.; Hilser, V. J. Ensemble-based signatures of energy propagation in proteins: a new view of an old phenomenon. Proteins 2006, 62, 728-738.

[113] Liu, T.; Whitten, S. T.; Hilser, V. J. Functional residues serve a dominant role in mediating the cooperativity of the protein ensemble. Proc Natl Acad Sci U S A 2007, 104, 4347-4352.

[114] Schrank, T. P.; Bolen, D. W.; Hilser, V. J. Rational modulation of conformational fluctuations in adenylate kinase reveals a local unfolding mechanism for allostery and functional adaptation in proteins. Proc Natl Acad Sci U S A 2009, 106, 16984-16989.

[115] Antal, M. A.; Bode, C.; Csermely, P. Perturbation waves in proteins and protein networks: applications of percolation and game theories in signaling and drug design. Curr Protein Pept Sci 2009, 10, 161-172.
[116] Leitner, D. M. Energy flow in proteins. Annu Rev Phys Chem 2008, 59, 233-259.

[117] Morita, H.; Takano, M. Residue network in protein native structure belongs to the universality class of a three-dimensional critical percolation cluster. Phys Rev E Stat Nonlin Soft Matter Phys 2009, 79, 020901.

[118] Leitner, D. M. Frequency-resolved communication maps for proteins and other nanoscale materials. J Chem Phys 2009, 130, 195101.

[119] Piazza, F.; Sanejouand, Y. H. Energy transfer in nonlinear network models of proteins. Europhys Lett 2009, 88, 68001.

[120] Piazza, F.; Sanejouand, Y. H. Long-range energy transfer in proteins. Phys Biol 2009, 6, 046014.

[121] Erman, B. Relationships between ligand binding sites, protein architecture and correlated paths of energy and conformational fluctuations. Phys Biol 2011, 8, 056003.

[122] Martinez, L.; Figueira, A. C. M.; Webb, P.; Polikarpov, I.; Skaf, M. $\mathrm{S}$. Mapping the intramolecular vibrational energy flow in proteins reveals functionally important residues. J Phys Chem Lett 2011, 2, 2073-2078.

[123] Ota, N.; Agard, D. A. Intramolecular signaling pathways revealed by modeling anisotropic thermal diffusion. J Mol Biol 2005, 351, 345-354.

[124] Burendahl, S.; Nilsson, L. Computational studies of LXR molecular interactions reveal an allosteric communication pathway. Proteins 2012, 80, 294-306.

[125] Sharp, K.; Skinner, J. J. Pump-probe molecular dynamics as a tool for studying protein motion and long range coupling. Proteins 2006, 65, 347-361.

[126] Ma, C. W.; Xiu, Z. L.; Zeng, A. P. A new concept to reveal protein dynamics based on energy dissipation. PLoS One 2011, 6, e26453.

[127] Ma, C. W.; Xiu, Z. L.; Zeng, A. P. Discovery of intramolecular signal transduction network based on a new protein dynamics model of energy dissipation. PLoS One 2012, 7, e31529.

[128] Ishikura, T.; Yamato, T. Energy transfer pathways relevant for long-range intramolecular signaling of photosensory protein revealed by microscopic energy conductivity analysis. Chem Phys Lett 2006, 432, 533-537.

[129] Ferreiro, D. U.; Hegler, J. A.; Komives, E. A.; Wolynes, P. G. Localizing frustration in native proteins and protein assemblies. Proc Natl Acad Sci U S A 2007, 104, 19819-19824.

[130] Ferreiro, D. U.; Hegler, J. A.; Komives, E. A.; Wolynes, P. G. On the role of frustration in the energy landscapes of allosteric proteins. Proc Natl Acad Sci U S A 2011, 108, 3499-3503.

[131] Gaspar, M. E.; Csermely, P. Rigidity and flexibility of biological networks. Brief Funct Genomics 2012, 11, 443-456.

[132] Jacobs, D. J.; Rader, A. J.; Kuhn, L. A.; Thorpe, M. F. Protein flexibility predictions using graph theory. Proteins 2001, 44, 150165 .

[133] Jacobs, D. J.; Dallakyan, S.; Wood, G. G.; Heckathorne, A Network rigidity at finite temperature: relationships between thermodynamic stability, the nonadditivity of entropy, and cooperativity in molecular systems. Phys Rev E Stat Nonlin Soft Matter Phys 2003, 68, 061109.

[134] Rader, A. J.; Brown, S. M. Correlating allostery with rigidity. Mol Biosyst 2011, 7, 464-471.

[135] Dixit, A.; Verkhivker, G. M. Probing molecular mechanisms of the Hsp90 chaperone: biophysical modeling identifies key regulators of functional dynamics. PLoS One 2012, 7, e37605.

[136] Qi, Y.; Wang, Q.; Tang, B.; Lai, L. Identifying allosteric binding sites in proteins with a two-state Go model for novel allosteric effector discovery. J Chem Theory Comput 2012, 8, 2962-2971.

[137] Demerdash, O. N.; Daily, M. D.; Mitchell, J. C. Structure-based predictive models for allosteric hot spots. PLoS Comput Biol 2009, 5 , e1000531

[138] Dhulesia, A.; Gsponer, J.; Vendruscolo, M. Mapping of two networks of residues that exhibit structural and dynamical changes upon binding in a PDZ domain protein. J Am Chem Soc 2008, 130, 8931-8939.

[139] Itoh, K.; Sasai, M. Statistical mechanics of protein allostery: roles of backbone and side-chain structural fluctuations. J Chem Phys 2011, 134, 125102 .

[140] Dubay, K. H.; Bothma, J. P.; Geissler, P. L. Long-range intraprotein communication can be transmitted by correlated side-chain fluctuations alone. PLoS Comput Biol 2011, 7, e1002168. 
[141] Sengupta, D.; Kundu, S. Do topological parameters of amino acids within protein contact networks depend on their physico-chemical properties? Physica A 2012, 391, 4266-4278.

[142] Huang, J.; Kawashima, S.; Kanehisa, M. New amino acid indices based on residue network topology. Genome Inform 2007, 18, 152161.

[143] Benson, N. C.; Daggett, V. A chemical group graph representation for efficient high-throughput analysis of atomistic protein simulations. J Bioinform Comput Biol 2012, 10, 1250008.

[144] Hilser, V. J.; Thompson, E. B. Intrinsic disorder as a mechanism to optimize allosteric coupling in proteins. Proc Natl Acad Sci U S A 2007, 104, 8311-8315.

[145] Gnanasekaran, R.; Agbo, J. K.; Leitner, D. M. Communication maps computed for homodimeric hemoglobin: computational study of water-mediated energy transport in proteins. J Chem Phys 2011, $135,065103$.

[146] Csermely, P., Weak Links: Stabilizers of Complex Systems from Proteins to Social Networks. Springer: Heidelberg, 2006.

[147] Barabasi, A. L.; Oltvai, Z. N. Network biology: understanding the cell's functional organization. Nat Rev Genet 2004, 5, 101-113.

[148] Ma, B.; Nussinov, R. Amplification of signaling via cellular allosteric relay and protein disorder. Proc Natl Acad Sci U S A 2009, 106, 6887-6888.

[149] Taatjes, D. J. The human Mediator complex: a versatile, genomewide regulator of transcription. Trends Biochem Sci 2010, 35, 315322.

[150] Lariviere, L.; Plaschka, C.; Seizl, M.; Wenzeck, L.; Kurth, F.; Cramer, P. Structure of the Mediator head module. Nature 2012, 492, 448-451.

[151] Maslov, S.; Ispolatov, I. Propagation of large concentration changes in reversible protein-binding networks. Proc Natl Acad Sci U S A 2007, 104, 13655-13660.

[152] Bodenmiller, B.; Wanka, S.; Kraft, C.; Urban, J.; Campbell, D.; Pedrioli, P. G.; Gerrits, B.; Picotti, P.; Lam, H.; Vitek, O.; Brusniak, M. Y.; Roschitzki, B.; Zhang, C.; Shokat, K. M.; Schlapbach, R.; Colman-Lerner, A.; Nolan, G. P.; Nesvizhskii, A. I.; Peter, M.; Loewith, R.; von Mering, C.; Aebersold, R. Phosphoproteomic analysis reveals interconnected system-wide responses to perturbations of kinases and phosphatases in yeast. Sci Signal 2010, 3 , rs4.

[153] Stumpf, M. P.; Thorne, T.; de Silva, E.; Stewart, R.; An, H. J.; Lappe, M.; Wiuf, C. Estimating the size of the human interactome. Proc Natl Acad Sci U S A 2008, 105, 6959-6964.

[154] Stelzl, U.; Worm, U.; Lalowski, M.; Haenig, C.; Brembeck, F. H.; Goehler, H.; Stroedicke, M.; Zenkner, M.; Schoenherr, A.; Koeppen, S.; Timm, J.; Mintzlaff, S.; Abraham, C.; Bock, N.; Kietzmann, S.; Goedde, A.; Toksoz, E.; Droege, A.; Krobitsch, S.; Korn, B.; Birchmeier, W.; Lehrach, H.; Wanker, E. E. A human protein-protein interaction network: a resource for annotating the proteome. Cell 2005, 122, 957-968.

[155] Rual, J. F.; Venkatesan, K.; Hao, T.; Hirozane-Kishikawa, T.; Dricot, A.; Li, N.; Berriz, G. F.; Gibbons, F. D.; Dreze, M.; AyiviGuedehoussou, N.; Klitgord, N.; Simon, C.; Boxem, M.; Milstein, S.; Rosenberg, J.; Goldberg, D. S.; Zhang, L. V.; Wong, S. L.; Franklin, G.; Li, S.; Albala, J. S.; Lim, J.; Fraughton, C.; Llamosas, E.; Cevik, S.; Bex, C.; Lamesch, P.; Sikorski, R. S.; Vandenhaute, J.; Zoghbi, H. Y.; Smolyar, A.; Bosak, S.; Sequerra, R.; DoucetteStamm, L.; Cusick, M. E.; Hill, D. E.; Roth, F. P.; Vidal, M. Towards a proteome-scale map of the human protein-protein interaction network. Nature 2005, 437, 1173-1178.

[156] Burkard, T. R.; Planyavsky, M.; Kaupe, I.; Breitwieser, F. P.; Burckstummer, T.; Bennett, K. L.; Superti-Furga, G.; Colinge, J. Initial characterization of the human central proteome. BMC Syst Biol 2011, 5, 17 .

[157] Havugimana, P. C.; Hart, G. T.; Nepusz, T.; Yang, H.; Turinsky, A. L.; Li, Z.; Wang, P. I.; Boutz, D. R.; Fong, V.; Phanse, S.; Babu, M.; Craig, S. A.; Hu, P.; Wan, C.; Vlasblom, J.; Dar, V. U.; Bezginov, A.; Clark, G. W.; Wu, G. C.; Wodak, S. J.; Tillier, E. R.; Paccanaro, A.; Marcotte, E. M.; Emili, A. A census of human soluble protein complexes. Cell 2012, 150, 1068-1081.

[158] Tegner, J.; Bjorkegren, J. Perturbations to uncover gene networks. Trends Genet 2007, 23, 34-41.

[159] Tompa, P.; Rose, G. D. The Levinthal paradox of the interactome. Protein Sci 2011, 20, 2074-2079.
[160] Kim, P. M.; Lu, L. J.; Xia, Y.; Gerstein, M. B. Relating threedimensional structures to protein networks provides evolutionary insights. Science 2006, 314, 1938-1941.

[161] Bhardwaj, N.; Abyzov, A.; Clarke, D.; Shou, C.; Gerstein, M. B. Integration of protein motions with molecular networks reveals different mechanisms for permanent and transient interactions. Protein Sci 2011, 20, 1745-1754.

[162] Pache, R. A.; Aloy, P. A novel framework for the comparative analysis of biological networks. PLoS One 2012, 7, e31220.

[163] Sanchez Claros, C.; Tramontano, A. Detecting mutually exclusive interactions in protein-protein interaction maps. PLoS One 2012, 7, e38765.

[164] Conn, P. J.; Christopoulos, A.; Lindsley, C. W. Allosteric modulators of GPCRs: a novel approach for the treatment of CNS disorders. Nat Rev Drug Discov 2009, 8, 41-54.

[165] Kenakin, T. P. '7TM receptor allostery: putting numbers to shapeshifting proteins. Trends Pharmacol Sci 2009, 30, 460-469.

[166] Kenakin, T.; Miller, L. J. Seven transmembrane receptors as shapeshifting proteins: the impact of allosteric modulation and functional selectivity on new drug discovery. Pharmacol Rev 2010, 62, 265-304.

[167] Hammond, A. S.; Rodriguez, A. L.; Townsend, S. D.; Niswender, C. M.; Gregory, K. J.; Lindsley, C. W.; Conn, P. J. Discovery of a Novel Chemical Class of mGlu(5) Allosteric Ligands with Distinct Modes of Pharmacology. ACS Chem Neurosci 2010, 1, 702-716.

[168] Bray, D.; Duke, T. Conformational spread: the propagation of allosteric states in large multiprotein complexes. Anпи Rev Biophys Biomol Struct 2004, 33, 53-73.

[169] Corcoran, R. B.; Dias-Santagata, D.; Bergethon, K.; Iafrate, A. J.; Settleman, J.; Engelman, J. A. BRAF gene amplification can promote acquired resistance to MEK inhibitors in cancer cells harboring the BRAF V600E mutation. Sci Signal 2010, 3, ra84.

[170] Johannessen, C. M.; Boehm, J. S.; Kim, S. Y.; Thomas, S. R.; Wardwell, L.; Johnson, L. A.; Emery, C. M.; Stransky, N.; Cogdill, A. P.; Barretina, J.; Caponigro, G.; Hieronymus, H.; Murray, R. R.; Salehi-Ashtiani, K.; Hill, D. E.; Vidal, M.; Zhao, J. J.; Yang, X.; Alkan, O.; Kim, S.; Harris, J. L.; Wilson, C. J.; Myer, V. E.; Finan, P. M.; Root, D. E.; Roberts, T. M.; Golub, T.; Flaherty, K. T.; Dummer, R.; Weber, B. L.; Sellers, W. R.; Schlegel, R.; Wargo, J. A.; Hahn, W. C.; Garraway, L. A. COT drives resistance to RAF inhibition through MAP kinase pathway reactivation. Nature 2010, 468, 968-972.

[171] Efeyan, A.; Sabatini, D. M. mTOR and cancer: many loops in one pathway. Curr Opin Cell Biol 2010, 22, 169-176.

[172] Dowling, R. J.; Topisirovic, I.; Fonseca, B. D.; Sonenberg, N. Dissecting the role of mTOR: lessons from mTOR inhibitors. Biochim Biophys Acta 2010, 1804, 433-439.

[173] Ohlson, S. Designing transient binding drugs: a new concept for drug discovery. Drug Discov Today 2008, 13, 433-439.

[174] Huang, S.; Ernberg, I.; Kauffman, S. Cancer attractors: a systems view of tumors from a gene network dynamics and developmental perspective. Semin Cell Dev Biol 2009, 20, 869-876.

[175] del Sol, A.; Balling, R.; Hood, L.; Galas, D. Diseases as network perturbations. Curr Opin Biotechnol 2010, 21, 566-571.

[176] Wang, J.; Li, Z. X.; Qiu, C. X.; Wang, D.; Cui, Q. H. The relationship between rational drug design and drug side effects. Brief Bioinform 2012, 13, 377-382.

[177] Korcsmaros, T.; Farkas, I. J.; Szalay, M. S.; Rovo, P.; Fazekas, D.; Spiro, Z.; Bode, C.; Lenti, K.; Vellai, T.; Csermely, P. Uniformly curated signaling pathways reveal tissue-specific cross-talks and support drug target discovery. Bioinformatics 2010, 26, 2042-2050.

[178] Bourbon, H. M. Comparative genomics supports a deep evolutionary origin for the large, four-module transcriptional mediator complex. Nucleic Acids Res 2008, 36, 3993-4008.

[179] Hamp, T.; Rost, B. Alternative protein-protein interfaces are frequent exceptions. PLoS Comput Biol 2012, 8, e1002623.

[180] Levy, E. D.; De, S.; Teichmann, S. A. Cellular crowding imposes global constraints on the chemistry and evolution of proteomes. Proc Natl Acad Sci U S A 2012, 109, 20461-20466.

[181] Tompa, P. On the supertertiary structure of proteins. Nat Chem Biol 2012, 8, 597-600.

[182] Pommier, Y.; Cherfils, J. Interfacial inhibition of macromolecular interactions: nature's paradigm for drug discovery. Trends Pharmacol Sci 2005, 26, 138-145. 
[183] Keskin, O.; Gursoy, A.; Ma, B.; Nussinov, R. Towards drugs targeting multiple proteins in a systems biology approach. Curr Top Med Chem 2007, 7, 943-951.

[184] Gordo, S.; Giralt, E. Knitting and untying the protein network: modulation of protein ensembles as a therapeutic strategy. Protein Sci 2009, 18, 481-493.

[185] Lee, G. M.; Shahian, T.; Baharuddin, A.; Gable, J. E.; Craik, C. S. Enzyme inhibition by allosteric capture of an inactive conformation. J Mol Biol 2011, 411, 999-1016.

[186] Nussinov, R. Allosteric modulators can restore function in an amino acid neurotransmitter receptor by slightly altering intramolecular communication pathways. Br J Pharmacol 2012, 165, 2110-2112.

[187] Kim, D. N.; Altschuler, J.; Strong, C.; McGill, G.; Bathe, M. Conformational dynamics data bank: a database for conformational dynamics of proteins and supramolecular protein assemblies. Nucleic Acids Res 2011, 39, D451-455.

[188] Keskin, O.; Nussinov, R.; Gursoy, A. PRISM: protein-protein interaction prediction by structural matching. Methods Mol Biol 2008, 484, 505-521.

[189] Isin, B.; Estiu, G.; Wiest, O.; Oltvai, Z. N. Identifying Ligand Binding Conformations of the $\beta 2$-Adrenergic Receptor by Using Its Agonists as Computational Probes. PLoS One 2012, 7, e50186.

[190] Chennubhotla, C.; Bahar, I. Markov methods for hierarchical coarse-graining of large protein dynamics. J Comput Biol 2007, 14, 765-776

[191] Liu, Y.; Bahar, I. Toward understanding allosteric signaling mechanisms in the ATPase domain of molecular chaperones. Pac Symp Biocomput 2010, 269-280.

[192] Liu, Y.; Gierasch, L. M.; Bahar, I. Role of Hsp70 ATPase domain intrinsic dynamics and sequence evolution in enabling its functional interactions with NEFs. PLoS Comput Biol 2010, 6, e1000931.

[193] Su, J. G.; Xu, X. J.; Li, C. H.; Chen, W. Z.; Wang, C. X. Identification of key residues for protein conformational transition using elastic network model. J Chem Phys 2011, 135, 174101.

[194] Kovacs, I. A.; Palotai, R.; Szalay, M. S.; Csermely, P. Community landscapes: an integrative approach to determine overlapping network module hierarchy, identify key nodes and predict network dynamics. PLoS One 2010, 5, e12528.

[195] Farkas, I. J.; Korcsmaros, T.; Kovacs, I. A.; Mihalik, A.; Palotai, R.; Simko, G. I.; Szalay, K. Z.; Szalay-Beko, M.; Vellai, T.; Wang, S.; Csermely, P. Network-based tools for the identification of novel drug targets. Sci Signal 2011, 4, pt3.

[196] Ispolatov, I.; Maslov, S. Detection of the dominant direction of information flow and feedback links in densely interconnected regulatory networks. BMC Bioinformatics 2008, 9, 424.

[197] Jothi, R.; Balaji, S.; Wuster, A.; Grochow, J. A.; Gsponer, J.; Przytycka, T. M.; Aravind, L.; Babu, M. M. Genomic analysis reveals a tight link between transcription factor dynamics and regulatory network architecture. Mol Syst Biol 2009, 5, 294.

[198] Cheng, C. Y.; Hu, Y. J. Extracting the abstraction pyramid from complex networks. BMC Bioinformatics 2010, 11, 411.

[199] Hartsperger, M. L.; Strache, R.; Stumpflen, V. HiNO: an approach for inferring hierarchical organization from regulatory networks. PLoS One 2010, 5, e13698.
[200] Rosvall, M.; Bergstrom, C. T. Multilevel compression of random walks on networks reveals hierarchical organization in large integrated systems. PLoS One 2011, 6, e18209.

[201] Mones, E.; Vicsek, L.; Vicsek, T. Hierarchy measure for complex networks. PLoS One 2012, 7, e33799.

[202] Banerjee, S. J.; Roy, S. Key to network controllability. ArXiv.org ePrint archive [Online], 2012. http://arxiv.org/abs/1209.3737 (accessed Jan 3, 2013)

[203] Cornelius, S. P.; Kath, W. L.; Motter, A. E. Controlling complex networks with compensatory perturbations. ArXiv.org e-Print archive [Online], 2011. http://arxiv.org/abs/1105.3726 (accessed Jan 3, 2013)

[204] Nepusz, T.; Vicsek, T. Controlling edge dynamics in complex networks. Nature Physics 2012, 8, 568-573.

[205] Liu, Y. Y.; Slotine, J. J.; Barabasi, A. L. Controllability of complex networks. Nature 2011, 473, 167-173.

[206] Wang, W. X.; Ni, X.; Lai, Y. C.; Grebogi, C. Optimizing controllability of complex networks by minimum structural perturbations. Phys Rev E Stat Nonlin Soft Matter Phys 2012, 85 026115 .

[207] Cowan, N. J.; Chastain, E. J.; Vilhena, D. A.; Freudenberg, J. S.; Bergstrom, C. T. Nodal dynamics, not degree distributions, determine the structural controllability of complex networks. PLoS One 2012, 7, e38398.

[208] Ghosh, A.; Vishveshwara, S. Variations in clique and community patterns in protein structures during allosteric communication: investigation of dynamically equilibrated structures of methionyl tRNA synthetase complexes. Biochemistry 2008, 47, 11398-11407.

[209] Liu, J.; Nussinov, R. Allosteric effects in the marginally stable von Hippel-Lindau tumor suppressor protein and allostery-based rescue mutant design. Proc Natl Acad Sci U S A 2008, 105, 901-906.

[210] Halabi, N.; Rivoire, O.; Leibler, S.; Ranganathan, R. Protein sectors: evolutionary units of three-dimensional structure. Cell 2009, 138, 774-786.

[211] Joseph, R. E.; Xie, Q.; Andreotti, A. H. Identification of an allosteric signaling network within Tec family kinases. $\mathrm{J} \mathrm{Mol} \mathrm{Biol}$ 2010, 403, 231-242.

[212] Jeon, J.; Nam, H. J.; Choi, Y. S.; Yang, J. S.; Hwang, J.; Kim, S. Molecular evolution of protein conformational changes revealed by a network of evolutionarily coupled residues. Mol Biol Evol 2011, 28, 2675-2685.

[213] Li, Y.; Wen, Z.; Xiao, J.; Yin, H.; Yu, L.; Yang, L.; Li, M. Predicting disease-associated substitution of a single amino acid by analyzing residue interactions. BMC Bioinformatics 2011, 12, 14.

[214] Wang, X.; Wei, X.; Thijssen, B.; Das, J.; Lipkin, S. M.; Yu, H Three-dimensional reconstruction of protein networks provides insight into human genetic disease. Nat Biotechnol 2012, 30, 159164.

[215] Huang, Z.; Zhu, L.; Cao, Y.; Wu, G.; Liu, X.; Chen, Y.; Wang, Q.; Shi, T.; Zhao, Y.; Wang, Y.; Li, W.; Li, Y.; Chen, H.; Chen, G.; Zhang, J. ASD: a comprehensive database of allosteric proteins and modulators. Nucleic Acids Res 2011, 39, D663-669.

[216] Kar, G.; Keskin, O.; Gursoy, A.; Nussinov, R. Allostery and population shift in drug discovery. Curr Opin Pharmacol 2010, 10, 715-722.

[217] Castoreno, A. B.; Eggert, U. S. Small molecule probes of cellular pathways and networks. ACS Chem Biol 2011, 6, 86-94. 